\title{
Carbon Monoxide Oxidation over Gold Nanoparticles Deposited onto Alumina Film Grown on Mo(110) Substrate: An Effect of Charge Tunneling through the Oxide Film
}

\author{
Tamerlan Magkoev (D)
}

check for updates

Citation: Magkoev, T. Carbon Monoxide Oxidation over Gold Nanoparticles Deposited onto Alumina Film Grown on Mo(110) Substrate: An Effect of Charge Tunneling through the Oxide Film. Materials 2021, 14, 485. https://doi. org/10.3390/ma14030485

Academic Editor: Jaeyong Kim Received: 29 December 2020

Accepted: 18 January 2021

Published: 20 January 202

Publisher's Note: MDPI stays neutral with regard to jurisdictional claims in published maps and institutional affiliations.

Copyright: (C) 2021 by the author. Licensee MDPI, Basel, Switzerland. This article is an open access article distributed under the terms and conditions of the Creative Commons Attribution (CC BY) license (https:/ / creativecommons.org/licenses/by/ $4.0 /)$.
Laboratory of Surface Physics and Catalysis, Department of Condensed Matter Physics, North Ossetian State University, Vatutina 44-46, 362025 Vladikavkaz, Russia; t_magkoev@mail.ru; Tel.: +7-91-8822-4595

\begin{abstract}
Formation of gold nanosized particles supported by aluminum oxide film grown on $\mathrm{Mo}(110)$ substrate and oxidation of carbon monoxide molecules on their surface have been in-situ studied in ultra-high vacuum by means of Auger electron spectroscopy (AES), reflection-absorption infrared spectroscopy (RAIRS), low energy electron diffraction (LEED), atomic force microscopy (AFM), temperature-programmed desorption (TPD), and work function measurements. The main focus was to follow how the thickness of the alumina film influences the efficiency of CO oxidation in an attempt to find out evidence of the possible effect of electron tunneling between the metal substrate and the Au particle through the oxide interlayer. Providing the largest degree of surface identity of the studied metal/oxide system at different thicknesses of the alumina film (two, four, six, and eight monolayers), it was found that the $\mathrm{CO}$ oxidation efficiency, defined as $\mathrm{CO}_{2}$ to $\mathrm{CO}$ TPD peaks intensity ratio, exponentially decays with the oxide film thickness growth. Taking into account the known fact that the CO oxidation efficiency depends on the amount of excess charge acquired by $\mathrm{Au}$ particle, the latter suggests that electron tunneling adds efficiency to the oxidation process, although not significantly.
\end{abstract}

Keywords: surface reaction; oxide supported metal nanoparticles; carbon monoxide oxidation; electron tunneling; gold; alumina

\section{Introduction}

Metal nanoparticles on oxides are used in a variety of applications, one of them being heterogeneous catalysis [1]. This motivates extensive studies of corresponding model metal/oxide supported catalysts to better understand the elementary steps involved in reactions on their surface [2]. One of the key points activating reactions on the surface of supported metal particles is the value of the charge that the particle acquires due to the charge transfer between the oxide support and the metal particle [3-5]. For instance, for $\mathrm{Au} / \mathrm{TiO}_{2}$ (110) Okazaki et al. [6] have shown via density functional theory (DFT) calculations that the electron transfer occurs from the six-fold Ti atom to the Au atom for the Ti-rich surface, while from the Au atom to the in-plane and inner oxygen atoms for the O-rich surface, which closely relates to the catalytic property of the $\mathrm{Au} / \mathrm{TiO}_{2}$ system. A similar situation holds for Au supported on the other oxide- $\mathrm{MgO}$, for which Sanchez et al. [7] have shown that there is partial electron transfer from the surface to the gold cluster, which plays an essential role in the activation of nanosize gold clusters as catalysts for the $\mathrm{CO}$ combustion reaction. Later on, Goodman and coworkers [8] also found magnesium oxide to be an effective electron donor to negatively charge supported Au particles via charge transfer from anionic vacancies (F-centers) and thus activating them as catalysts for $\mathrm{CO}$ oxidation. Catalytic activation of LiF supported $\mathrm{Au}$ particles via charge transfer from anionic vacancies has also been recently reported by Tvauri et al. [9]. Electron-rich Au nanoparticles are predicted to adsorb dioxygen more strongly and to activate the $\mathrm{O}-\mathrm{O}$ bond via charge transfer from Au to form a superoxo-like species [10], as well as facilitating the 
activation of $\mathrm{CO}$ [11]. For metal particles deposited on nano-thick oxide layers grown on metallic substrates, there is an additional channel of charge transfer to/from the metal particles via electron tunneling through the oxide interlayer [12]. For example, deposition of Cs onto ultrathin alumina films supported on $\mathrm{Mo}(110)$ induces large $(0.9-1.1 \mathrm{eV})$ positive shifts in the $\mathrm{BE}$ of $\mathrm{O} \mathrm{KVV}, \mathrm{O} 1 \mathrm{~s}, \mathrm{Al} 2 \mathrm{p}$ feature of alumina film [13]. Aluminum deposition on an alumina layer grown on $\mathrm{NiAl}(110)$ results in a shift of the oxide component in $\mathrm{Al}$ $2 \mathrm{p}, \mathrm{O} 1 \mathrm{~s}$, and $\mathrm{O} 2 \mathrm{p}$ to higher $\mathrm{BE}$ by $0.47 \pm 0.03 \mathrm{eV}$ [14]. A similar shift to higher $\mathrm{BE}$ in the range of $0.5 \mathrm{eV}$ was detected while depositing $\mathrm{V}$ onto the same oxide surface [15]. Considering that $\mathrm{Cs}, \mathrm{Al}$, and $\mathrm{V}$ have low work functions, a charge transfer is expected to take place from Mo to Cs [16], from NiAl to Al [14], and from NiAl to V [15]. These and similar studies mainly deal with the "static" state of supported particles, with no manifestation of how electron tunneling through oxide interlayer affects the chemical reaction on their surface. In relation to this, the aim of the present study was to find out the definite evidence of the effect of charge transfer to/from the metal particle via the electron tunneling through the supporting oxide film, grown on the conducting metal substrate, upon the possible chemical reaction over the supported particle. To minimize the effect caused by metal/oxide interaction, the noble metal $(\mathrm{Au})$ and stable non-reducible oxide $\left(\mathrm{Al}_{2} \mathrm{O}_{3}\right)$, as well as representative elementary reactants $\left(\mathrm{CO}+\mathrm{O}_{2}\right)$, are used.

\section{Experimental}

Investigations were carried out in a modified ultra-high vacuum (UHV) VG Escalab Mk II system (base pressure: $3 \times 10^{-10}$ mbar) enabling Auger electron spectroscopy (AES) with the aid of a single-pass cylindrical mirror analyzer with a coaxial gun, low energy electron diffraction (LEED) using rear view four-grid optics, reflection-absorption infrared spectroscopy (RAIRS, Nicolet, Seattle, WA, USA) with grazing incidence and reflection infrared beams, temperature-programmed desorption (TPD) using quadrupole mass-spectrometer, work function (WF) measurements by Anderson's method, and atomic force microscopy (AFM) with the aid of an Omicron Nanoprobe (Omicron GmbH, Hamburg, Germany) instrument. The p-polarized light used in RAIRS provides sensitivity to molecular vibrations normal to the surface plane. This is the case for diatomic polar molecules like $\mathrm{CO}$, which adsorb in an upright or tilted geometry on most metallic and nonmetallic substrates [17]. An aluminum oxide film of controlled thickness and structure was grown on $\mathrm{Mo}(110)$ substrate held at elevated temperature via a well-known procedure of reactive thermal evaporation of aluminum atoms from Knudsen cell in an oxygen ambient at a partial pressure of about $10^{-7}$ mbar [18]. The thickness of the grown alumina film was determined by the deposited amount of metallic aluminum by the well-known procedure described by Goodman and coworkers $[18,19]$. The Mo(110) support as a refractory metal was chosen as it enables high-temperature treatment of the films to achieve equilibration and because of the close lattice match with $\alpha \mathrm{Al}_{2} \mathrm{O}_{3}(1000)$ to get epitaxial films even at very low thickness. The film thickness was estimated within the error of about $15 \%$ by measuring the aluminum atom flux via quartz microbalance and the Mo MNV (188 eV) Auger intensity attenuation upon the oxide film growth, according to the procedure described by Goodman and coworkers [18,19]. The Al deposition flux was additionally controlled via the work function change of $\mathrm{Mo}(110)$ substrate upon aluminum submonolayer film growth [20]. The amount of deposited metallic aluminum was controlled by the deposition flux and time. The Au atoms were deposited on alumina films by thermal evaporation of bulk Au (purity: $99.9999 \%$ ) via the Knudsen cell at substrates held at room temperature and then annealed to $500 \mathrm{~K}$ for $3 \mathrm{~min}$ to achieve equilibration. The Au coverage was determined by quartz microbalance and verified by substrate $(\mathrm{O} \mathrm{KVV}, 502 \mathrm{eV})$ Auger signal attenuation. The surface concentration of Au atoms of $1.45 \times 10^{15} \mathrm{~cm}^{-2}$ was considered to be equal to 1 MLE (monolayer equivalent) of Au. Commercially available carbon monoxide and oxygen of research-grade quality were controllably admitted into the vacuum chamber through UHV leak valves. It is considered that exposure of $1 \mathrm{~L}$ corresponds to $10^{-6}$ Torr $\times 1 \mathrm{~s}$. The sample holder, on which $\mathrm{Mo}(110)$ crystal was mounted coaxially to quartz mi- 
crobalance, enabled cooling the sample down to $90 \mathrm{~K}$ via attached liquid nitrogen reservoir and annealing to moderate temperatures (1000-1500 K) by direct current flow across the substrate, and to $2700 \mathrm{~K}$ by electron bombardment.

\section{Results and Discussion}

Taking into account that the electron tunneling probability through the oxide dielectric layer depends exponentially upon its thickness, the measurements for $\mathrm{CO}$ oxidation efficiency over $\mathrm{Au} / \mathrm{Al}_{2} \mathrm{O}_{3} / \mathrm{Mo}(110)$ were done for different alumina interlayer thicknesses, namely two, four, six, and eight monolayers. As the surface reaction is very sensitive to the state of the surface, it was essential to ensure that the structural, electronic, and adsorption properties of alumina films of different thickness, as well as that of $\mathrm{Au} / \mathrm{Al}_{2} \mathrm{O}_{3}$, are the same in order not to mask the possible tunneling effect on the surface reaction. It is well established by numerous studies that two monolayer thick alumina film exhibits properties that resemble those of bulk alumina $[18,19,21-23]$. Moreover, beginning from this thickness, the film acquires dielectric properties [24-26]. The LEED patterns of alumina films of two, four, six, and eight monolayer thickness are the same and demonstrate hexagonal symmetry corresponding to $\alpha-\mathrm{Al}_{2} \mathrm{O}_{3}(1000)$, which is the case for equilibrium alumina films on $\operatorname{Mo}(110)[18,19,27]$ (Figure 1a,b). Aluminum interatomic Auger peak position, as well as its relative intensity against oxygen O KVV Auger line, are essentially the same for different alumina films studied. This indicates that the stoichiometry of the films is similar. A more precise check of the surface state of alumina films is the adsorption behavior of test species, like CO [28]. One of the most sensitive tools to probe such behavior is RAIRS due to its high resolution and sensitivity to adsorbed molecules, of which the vibrational mode is extremely sensitive to details of the structural and electronic state of the adsorbent [17]. The IR spectra in the stretching region of $\mathrm{CO}$ adsorbed at saturation coverage (exposure: $200 \mathrm{~L}$ ) on two, four, six, and eight monolayer thick alumina films cooled down to $90 \mathrm{~K}$, are shown in Figure 2. As seen, the spectra are very similar, indicating that the state of alumina film surface at all thicknesses studied is essentially the same. Since it is known that $\mathrm{CO}$ does not adsorb on alumina regular sites at $90 \mathrm{~K}$ [29], the observed IR band is likely attributed to the $\mathrm{CO}$ bound to oxide defect sites [30]. The same IR band position, intensity, and halfwidth allow one to assume that the defect nature and their density are similar for all alumina films. The quite low IR intensity (signal to noise ratio) suggests that the density of defects is rather low. The most reasonable nature of these defects is anionic vacancies, which anyway exist to a certain extent in structurally ordered mostly stoichiometric alumina films grown by reactive deposition [31]. They enhance sticking of $\mathrm{CO}$ molecules to alumina surface by switching backdonation to $\mathrm{CO} 2 \pi^{*}$ antibonding orbital via the negative charge of F-center, which otherwise is negligible at regular $\alpha-\mathrm{Al}_{2} \mathrm{O}_{3}(1000)$ sites [32].

Morphology of Au overlayers, deposited in an equivalent amount of 0.7 MLE onto alumina films of different thicknesses held at $500 \mathrm{~K}$ to achieve equilibration, demonstrates similarity, as seen from representative AFM images (Figure 1c,d). This is confirmed by the similarity of the Auger Au NVV to Al LVV intensity ratio (Figure 1e,f) - the value characterizing the relative area of the substrate covered by the adsorbate [19,33]. According to the DFT calculations of Jennison and coworkers [34,35], the Au bounds to $\alpha-\mathrm{Al}_{2} \mathrm{O}_{3}(1000)$ by ionic bond at submonolayer coverage, whereas at high coverage, when $3 \mathrm{D}$ islands form, the metal to oxide bonding is dominated by polarization effect. The feature of $\mathrm{Au}$ deposits for oxide supports is that they are basically neutral on the most stable adsorption sites $[12,36,37]$. To more precisely check whether the state of Au particles depends on alumina film thickness, the adsorption of $\mathrm{CO}$ molecules as a test specie was probed by RAIRS (CO exposure: $100 \mathrm{~L}$ ). All spectra consisting of a CO stretching vibrational band at $2098 \mathrm{~cm}^{-1}$ are almost identical to each other (Figure 3). Taking into account an extreme sensitivity of molecular vibrational modes to the details of the atomic and electronic structure of the substrate [17], the observed similarity of IR spectra points to the identical morphological and structural character of Au overlayer regardless of the underlying alumina film thickness. Since $\mathrm{CO}$ hardly adsorbs on the regular Au surface for 
the conditions used [38], the observed IR band can be attributed to molecules bound to undercoordinated sites available at Au clusters, as well as to the metal/oxide perimeter interface, as follows from numerous interpretations made for this and other types of oxide supported Au particles [12,29,38-40]. The lower CO stretching wavenumber on Au particle $\left(2098 \mathrm{~cm}^{-1}\right)$ compared to that on alumina support $\left(2115 \mathrm{~cm}^{-1}\right)$ can be rationalized in terms of larger charge backdonation from metal particle to $\mathrm{CO} 2 \pi^{*}$ antibonding orbital than from the anionic vacancy site of the oxide.
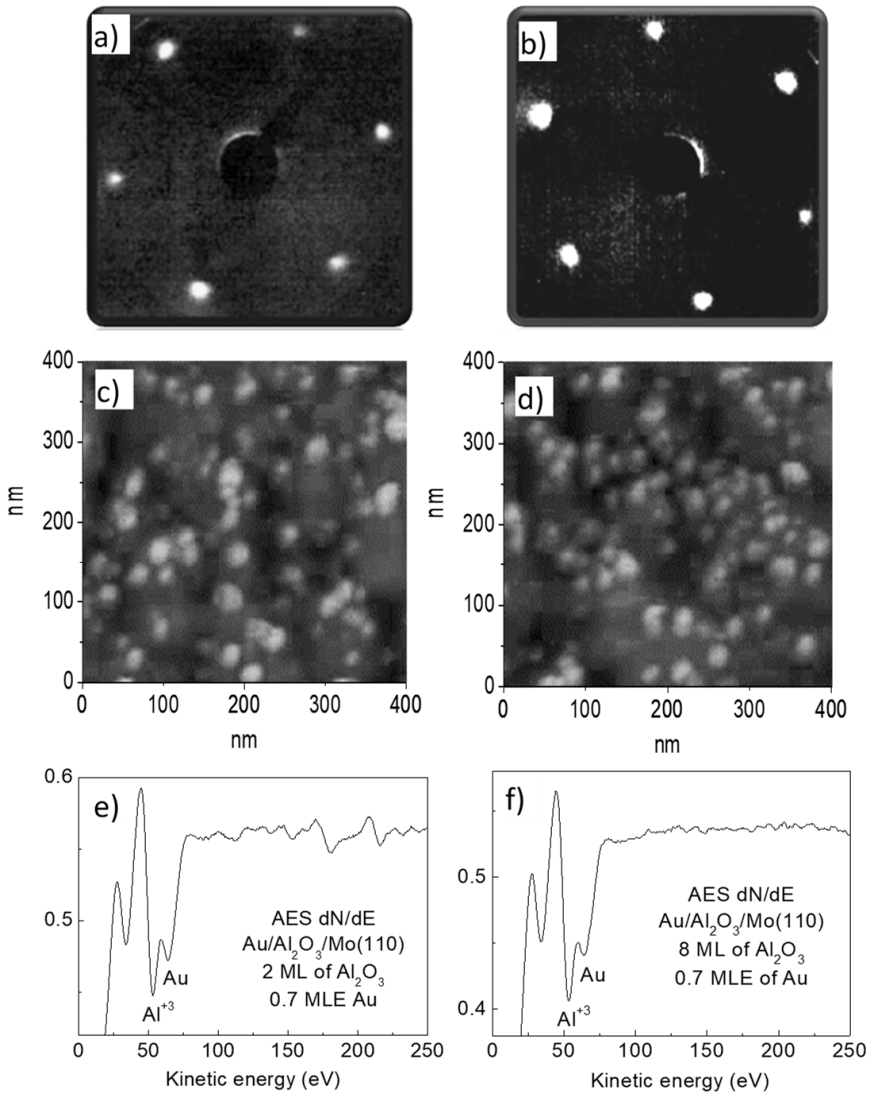

Figure 1. LEED patterns of alumina $2 \mathrm{~mL}$ (a) and $8 \mathrm{M}$ (b) thick films on $\mathrm{Mo}(110)$ substrate. AFM images of Au overlayers at a coverage 0.7 MLE on alumina $2 \mathrm{~mL}$ (c) and $8 \mathrm{M}$ (d) thick films. Gold was deposited onto alumina held at room temperature and then annealed to $500 \mathrm{~K}$ for 3 min. Auger spectra corresponding to AFM images: (e) $\rightarrow(\mathbf{c}),(\mathbf{f}) \rightarrow(\mathbf{d})$.

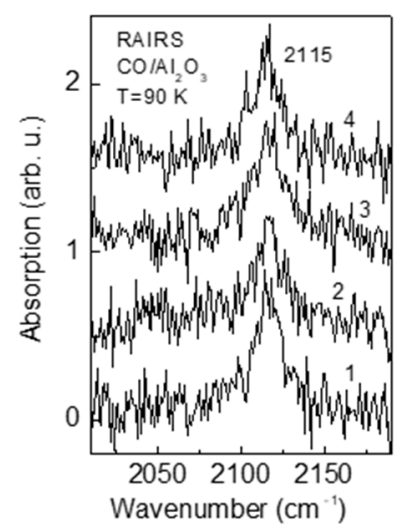

Figure 2. RAIR spectra in CO stretch region, obtained after 200 L-exposure of CO of alumina films $2 \mathrm{~mL}(1), 4 \mathrm{~mL}(2), 6 \mathrm{~mL}(3)$, and $8 \mathrm{~mL}$ (4) thick, held at a temperature of $90 \mathrm{~K}$. 


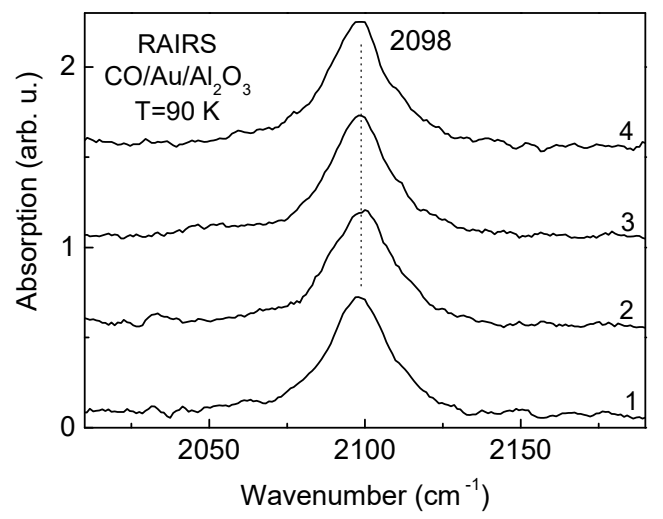

Figure 3. RAIR spectra in CO stretch region, obtained after $100 \mathrm{~L}$-exposure of CO of alumina supported Au overlayers at a coverage of 0.7 MLE, cooled down to $90 \mathrm{~K}$. Alumina film thickness: (1) $-2 \mathrm{~mL}$; (2) $-4 \mathrm{~mL}$; (3) $-6 \mathrm{~mL}$; (4) $-8 \mathrm{~mL}$.

Postadsorption of oxygen at an exposure of $100 \mathrm{~L}$ on $\mathrm{CO} / \mathrm{Au} / \mathrm{Al}_{2} \mathrm{O}_{3}$ held at $90 \mathrm{~K}$ leads to a blue shift of CO IR band by $5-6 \mathrm{~cm}^{-1}$ with no noticeable effect on its intensity. This rather small wavenumber shift is hardly due to displacement of $\mathrm{CO}$ to another adsorption site upon oxygen postadsorption. The latter would have been characterized by a notably higher molecular vibrational shift [41]. As it is known that molecular oxygen dissociates on Au ultrasmall particles [3], the observed IR blue shift can be accounted by $\mathrm{CO} 2 \pi^{*}$ antibonding orbital depopulation via partial charge transfer to higher electronaffinity atomic O $2 p$ level [42]. The observed quite low sensitivity of CO IR spectra to $\mathrm{O}_{2}$ postadsorption suggests that carbon monoxide and oxygen do not compete for the adsorption site on the supported gold particle at $90 \mathrm{~K}$. Instead, they likely reside at the adjacent sites, slightly affecting each other as manifested by the indicated CO IR band shift. According to DFT calculations [43], a hollow site consisting of four Au atoms in a square geometry appears well suited for atomic oxygen, whereas $\mathrm{CO}$ primarily bounds to atop $\mathrm{Au}$ cluster undercoordinated sites. A more pronounced effect ultimately resulting in molecular conversion $\left(\mathrm{CO}+\mathrm{O} \rightarrow \mathrm{CO}_{2}\right)$ appears upon heating to facilitate the migration of the adsorbed species across the surface and their activation. The TPD spectra of $\mathrm{CO}$ and $\mathrm{CO}_{2}$ species, acquired during continuous exposure of the $\mathrm{CO} / \mathrm{Au} / \mathrm{Al}_{2} \mathrm{O}_{3}$ to oxygen by backfilling the UHV chamber to a partial pressure of $10^{-6} \mathrm{mbar}$ are shown in Figure $4 \mathrm{a}, \mathrm{b}$. The temperature sweep rate was chosen as low as $1 \mathrm{~K} / \mathrm{s}$ to ensure equilibration of the process, and the TPD mass-spectrometer was adjusted for simultaneous registration of $\mathrm{CO}(\mathrm{m} / \mathrm{z}=28)$ and $\mathrm{CO}_{2}(\mathrm{~m} / \mathrm{z}=44)$ signals within one span. As seen, along with the desorption of $\mathrm{CO}$ (Figure 4a), the $\mathrm{CO}_{2}$ is also formed, although to a lower extent (Figure $4 \mathrm{~b}$ ). The mechanism of $\mathrm{CO}$ oxidation over oxide supported Au particles is under extensive study for the last several decades. It is considered to be a combination of a variety of parameters, such as particle size, morphology and structure, nature of the oxide support and its stoichiometry, state of the metal/oxide perimeter interface, reaction condition, etc. [12,29,38-40,44]. The common view in this regard is that the sign and magnitude of the charge of the Au particle, controlling activation of $\mathrm{CO}$ and $\mathrm{O}_{2}$ species, is a crucial point that determines the reaction pathway and rate [44].

Closer inspection of the TPD peak maxima (Figure 4, inlays) reveals that there is a definite feature that the $\mathrm{CO}$ signal grows and the $\mathrm{CO}_{2}$ signal concomitantly drops as the oxide film thickness increases. It means that the efficiency of $\mathrm{CO}$ oxidation is higher for thinner alumina interlayer film. This efficiency can be qualitatively defined as the ratio of $\mathrm{CO}_{2}$ to $\mathrm{CO}$ TPD peak intensity. The corresponding plot versus the alumina film thickness is presented in Figure 5. The plot quite well fits the exponential decay curve. The corresponding curve is plotted only to guide the eye as the precise thickness of the alumina film in the range from 0 to $8 \mathrm{~mL}$ is not unambiguously known. Taking into account the above-mentioned fact that the $\mathrm{CO}$ oxidation rate over supported Au particles 
depends on the value of their charge, the observed plot can be viewed as evidence that the tunneling of electrons of $\mathrm{Mo}(110)$ metal support through the alumina film to/from the $\mathrm{Au} / \mathrm{Al}_{2} \mathrm{O}_{3}$ reaction interface adds to the efficiency of $\mathrm{CO}$ oxidation. The reaction requires an excess charge, which is withdrawn/donated from/to the underlying conducting support via switching of tunneling effect through the insulating oxide interlayer. Charging of Au particles needed to activate the carbon monoxide oxidation steps "pumps" electrons from/to the metal support via the tunneling. This is in line with DFT studies indicating that the charging/discharging of the cluster during the catalytic cycle of $\mathrm{CO}$ oxidation strongly influences the energetics of all redox steps in catalytic conversions [45]. Also, according to previously reported results [46], the $\mathrm{O}_{2}$ upon adsorption gains approximately one electron, $\mathrm{O}-\mathrm{O}$ bond length elongates to 1.39-1.47 $\AA$, depending on if the cluster size and the O-O bond length correlates with the charge state of the molecule. Another point is that the charge rearrangement induced by the adsorbates occurs at the metal/oxide interface, as predicted via calculations [45], requires an electron reservoir, which in the present case is the underlying metal support, supplying charge via tunneling through the oxide film. The latter effect, however, is not dominant. As seen in Figure 5, the CO oxidation efficiency gain is not significant and is within c.a. $20 \%$.
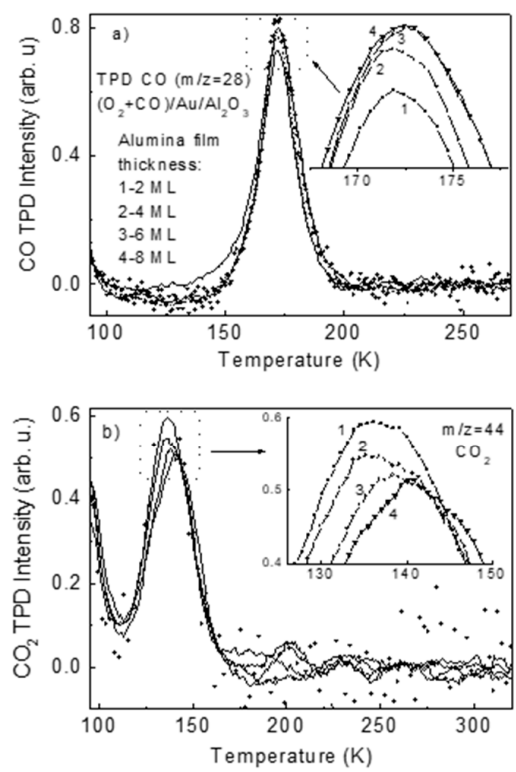

Figure 4. TPD spectra of $\mathrm{CO}(\mathbf{a})$ and $\mathrm{CO}_{2}(\mathbf{b})$, acquired during continuous exposure of $\mathrm{CO} / \mathrm{Au} / \mathrm{Al}_{2} \mathrm{O}_{3}$ to oxygen via backfilling the UHV chamber by $\mathrm{O}_{2}$ to a partial pressure of $10^{-6} \mathrm{mbar}$. Inlays depict the TPD peak maxima area. Alumina film thickness: (1)-2 mL; (2) $-4 \mathrm{~mL}$; (3) $-6 \mathrm{~mL}$; (4)-8 mL.

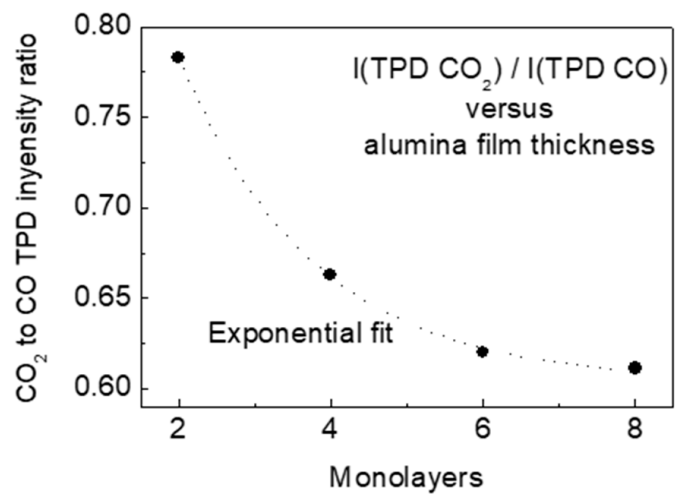

Figure 5. Ratio of TPD peak intensity of $\mathrm{CO}_{2}$ to $\mathrm{CO}$ versus the alumina film thickness (points) and the exponential fit (dotted line). 
Taking into account the possibility of electron tunneling to/from the Au particles through the oxide layer, one can expect that the charging of Au particles would be manifested by CO IR frequency shift with the oxide film thickness. The latter, however, is not the case. As seen in Figure 3, the corresponding CO stretching frequency is essentially the same regardless of the alumina film thickness. It means that in "static" mode the tunneling may be negligible. The effect mounts under reaction conditions when molecular oxidation requires extensive dynamical charging/recharging of the Au particle, the metal/oxide interface, and the reactants.

\section{Conclusions}

The structural, morphological, and adsorption properties of the Au overlayer on the ordered alumina film grown on $\mathrm{Mo}(110)$ substrate are similar regardless of the oxide film thickness, at least, in the range of two to eight monolayers. Unlike the regular surface of bulk $\mathrm{Au}$, the $\mathrm{CO}$ readily adsorbs on the alumina supported gold clusters held at a temperature of $90 \mathrm{~K}$, and presumably at the metal/oxide perimeter interface. This CO layer is quite slightly affected by the oxygen, dosed by backfilling the UHV chamber by $\mathrm{O}_{2}$ gas, suggesting that $\mathrm{CO}$ and oxygen occupy different adsorption sites. Heating of the formed $(\mathrm{CO}+\mathrm{O})$ adlayer results in desorption to the gas phase of both $\mathrm{CO}$ and $\mathrm{CO}_{2}$, the latter to a notably lower extent. This effect has a definite feature that the relative amount of desorbing $\mathrm{CO}_{2}$, compared to that of $\mathrm{CO}$, exponentially drops as the alumina film thickness increases. The latter, on account of the known fact that the $\mathrm{CO}$ oxidation efficiency depends on the amount of excess charge acquired by the Au particle, metal/oxide interface, and the reactants, is evidence that electron tunneling between the reaction area and the metal support through the oxide interlayer stimulates the oxidation process.

Funding: This research was funded by Russian Ministry of Science and Higher Education, grant number 075-15-2019-1887 and Goszadanie-2021.

Data Availability Statement: Data available on request due to privacy restrictions. The data presented in this study are available on request from the corresponding author. The data are not publicly available due to institutional internal regulations.

Acknowledgments: This work was supported by the Russian Ministry of Science and Higher Education under grant number 075-15-2019-1887 and Goszadanie-2021. Cooperation with Francisco Zaera (University of California, Riverside) is gratefully acknowledged.

Conflicts of Interest: The authors declare no conflict of interest.

\section{References}

1. Vedrine, J.C. Metal Oxides in Heterogeneous Catalysis; Elsevier: Amsterdam, The Netherlands, 2018; p. 618. ISBN 978-0-12-811631-9.

2. Chen, S.; Xiong, F.; Huang, W. Surface chemistry and catalysis of oxide model catalysts from single crystals to nanocrystals. Surf. Sci. Rep. 2019, 74, 100471. [CrossRef]

3. Picone, A.; Riva, M.; Brambilla, A.; Calloni, A.; Bussetti, G.; Finazzi, M.; Ciccacci, F.; Duò, L. Reactive metal-oxide interfaces: A microscopic view. Surf. Sci. Rep. 2016, 71, 32-76. [CrossRef]

4. Cai, Y.; Feng, Y.P. Review on charge transfer and chemical activity of TiO 2: Mechanism and applications. Prog. Surf. Sci. 2016, 91, 183-202. [CrossRef]

5. Honkala, K. Tailoring oxide properties: An impact on adsorption characteristics of molecules and metals. Surf. Sci. Rep. 2014, 69, 366-388. [CrossRef]

6. Okazaki, K.; Morikawa, Y.; Tanaka, S.; Tanaka, K.; Kohyama, M. Electronic structures of Au on TiO2(110) by first-principles calculations. Phys. Rev. B 2004, 69, 235404. [CrossRef]

7. Sanchez, A.; Abbet, S.; Heiz, U.; Schneider, W.-D.; Ha1kkinen, H.; Barnett, R.N.; Landman, U. When gold is not noble: Nanoscale gold catalysts. J. Phys. Chem. A 1999, 103, 9573-9578. [CrossRef]

8. Yan, Z.; Chinta, S.; Mohamed, A.A.; Fackler, J.J.P.; Goodman, D.W. The Role of F-Centers in Catalysis by Au Supported on MgO. J. Am. Chem. Soc. 2005, 127, 1604-1605. [CrossRef]

9. Tvauri, I.V.; Gergieva, B.; Magkoeva, V.; Grigorkina, G.; Bliev, A.; Ashkhotov, O.G.; Sozaev, V.; Fukutani, K.; Magkoev, T. Carbon monoxide oxidation on lithium fluoride supported gold nanoparticles: A significance of F-centers. Solid State Commun. 2015, 213-214, 42-45. [CrossRef] 
10. Yoon, B.; Häkkinen, H.; Landman, U. Interaction of O2with Gold Clusters: Molecular and Dissociative Adsorption. J. Phys. Chem. A 2003, 107, 4066-4071. [CrossRef]

11. Lopez, N.; Norskov, J.K.; Janssens, T.V.W.; Carlsson, A.; Puig-Molina, A.; Clausen, B.S.; Grunwaldt, J.D. The adhesion and shape of nanosized $\mathrm{Au}$ particles in a $\mathrm{Au} / \mathrm{TiO} 2$ catalyst. J. Catal. 2004, 225, 86-94. [CrossRef]

12. Fu, Q.; Wagner, T. Interaction of nanostructured metal overlayers with oxide surfaces. Surf. Sci. Rep. 2007, 62, 431-498. [CrossRef]

13. Heemeier, M.; Stempel, S.; Shaikhutdinov, S.K.; Libuda, J.; Baumer, M.; Oldman, R.J.; Jackson, S.D.; Freund, H.-J. On the thermal stability of metal particles supported on a thin alumina film. Surf. Sci. 2003, 523, 103-110. [CrossRef]

14. Libuda, J.; Frank, M.M.; Sandell, A.; Andersson, S.; Brühwiler, P.; Bäumer, M.; Mårtensson, N.; Freund, H.-J. Interaction of rhodium with hydroxylated alumina model substrates. Surf. Sci. 1997, 384, 106-119. [CrossRef]

15. Bäumer, M.; Biener, J.; Madix, R. Growth electronic properties and reactivity of vanadium deposited onto a thin alumina film. Surf. Sci. 1999, 432, 189-198. [CrossRef]

16. Brause, M.; Ochs, D.; Günster, J.; Mayer, T.; Braun, B.; Puchin, V.; Maus-Friedrichs, W.; Kempter, V. Cs adsorption on oxide films $\left(\mathrm{Al}_{2} \mathrm{O}_{3}, \mathrm{MgO}, \mathrm{SiO}_{2}\right)$. Surf. Sci. 1997, 383, 216-225. [CrossRef]

17. Hirschmugl, C.J. Frontiers in infrared spectroscopy at surfaces and interfaces. Surf. Sci. 2002, 500, 577-604. [CrossRef]

18. Goodman, D.W. Chemical and spectroscopic studies of metal oxide surfaces. J. Vac. Sci. Technol. A 1996, 14, 1526-1531. [CrossRef]

19. Wu, M.-C.; Goodman, D.W. Particulate Cu on Ordered Al2O3: Reactions with Nitric Oxide and Carbon Monoxide. J. Phys. Chem. 1994, 98, 9874-9881. [CrossRef]

20. Grigorkina, G.; Tvauri, I.V.; Kaloeva, A.; Burdzieva, O.; Sekiba, D.; Ogura, S.; Fukutani, K.; Magkoev, T.T. Reduction of nitric oxide with carbon monoxide on the Al-Mo(110) surface alloy. Solid State Commun. 2016, 233, 11-14. [CrossRef]

21. Jaeger, R.M.; Kuhlenbeck, H.; Freund, H.-J.; Wuttig, M.; Hoffmann, W.; Franchy, R.; Ibach, H. Formation of a well-ordered aluminium oxide overlayer by oxidation of $\mathrm{NiAl}(110)$. Surf. Sci. 1991, 259, 235-252. [CrossRef]

22. Becker, C.; Kandler, J.; Raaf, H.; Linke, R.; Pelster, T.; Dräger, M.; Tanemura, M.; Wandelt, K. Oxygen adsorption and oxide formation on Ni3Al (111). J. Vac. Sci. Technol. A 1998, 16, 1000-1005. [CrossRef]

23. Jennison, D.R.; Verdozzi, C.; Schultz, P.A.; Sears, M.P. Ab initio structural predictions for ultrathin aluminum oxide films on metallic substrates. Phys. Rev. B 1999, 59, 15605-15612. [CrossRef]

24. Magkoev, T.T.; Vladimirov, G.G. Aluminium oxide ultrathin-film growth on the Mo(110) surface: A work-function study. J. Phys. Condens. Matter 2001, 13, L655-L661. [CrossRef]

25. Magkoev, T.T.; Christmann, K.; Moutinho, A.; Murata, Y. Alumina vapour condensation on Mo() surface and adsorption of copper and gold atoms on the formed oxide layer. Surf. Sci. 2002, 515, 538-552. [CrossRef]

26. Magkoev, T.T.; Vladimirov, G.; Remar, D.; Moutinho, A. Comparative study of metal adsorption on the metal and the oxide surfaces. Solid State Commun. 2002, 122, 341-346. [CrossRef]

27. Frederick, B.G.; Apai, G.; Rhodin, T.N. Surface phonons in thin aluminum oxide films: Thickness, beam-energy, and symmetrymixing effects. Phys. Rev. B 1991, 44, 1880-1890. [CrossRef]

28. Fierro, J.L.G.; de la Banda, J.F.G. Chemisorption of probe molecules on metal oxides. Catal. Rev. 1986, 28, 265-333. [CrossRef]

29. Campbell, C.T. Ultrathin metal films and particles on oxide surfaces: Structural, electronic and chemisorptive properties. Surf. Sci. Rep. 1997, 27, 1-111. [CrossRef]

30. Zecchina, A.; Scarano, D.; Bordiga, S.; Ricchiardi, G.; Spoto, G.; Geobaldo, F. IR studies of CO and NO adsorbed on well characterized oxide single microcrystals. Catal. Today 1996, 27, 403-435. [CrossRef]

31. Renaud, G.; Villette, B.; Vilfan, I.; Bourret, A. Atomic structure of the $\alpha$-Al2O30001 $(\sqrt{ } 31 \times \sqrt{ } 31) \mathrm{R} \pm 90$ reconstruction. Phys. Rev. Lett. 1994, 73, 1825-1828. [CrossRef]

32. Casarin, M.; Maccato, C.; Vittadini, A. A Comparative Study of CO Chemisorption on Al2O3and Ti2O3Nonpolar Surfaces. J. Phys. Chem. B 2002, 106, 795-802. [CrossRef]

33. Ossicini, S.; Memeo, R.; Ciccacci, F. AES analysis of the growth mechanism of metal layers on metal surfaces. J. Vac. Sci. Technol. A 1985, 3, 387-391. [CrossRef]

34. Bogicevic, A.; Jennison, D.R. Variations in the Nature of Metal Adsorption on Ultrathin Al2O3Films. Phys. Rev. Lett. 1999, 82, 4050-4053. [CrossRef]

35. Mattsson, A.E.; Jennison, D. Computing accurate surface energies and the importance of electron self-energy in metal/metal-oxide adhesion. Surf. Sci. 2002, 520, L611-L618. [CrossRef]

36. Cao, Y.; Hu, S.; Huang, S.; Yu, M.; Wang, T.; Yan, S.S.; Xu, M. Manipulating the charge state of Au clusters on rutile TiO 2 (110) single crystal surfaces through molecular reactions probed by infrared spectroscopy. Phys. Chem. Chem. Phys. 2016, 18, 17660-17665. [CrossRef]

37. Márquez, A.M.; Graciani, J.; Sanz, J.F. Charge state of metal atoms on oxide supports: A systematic study based on simulated infrared spectroscopy and density functional theory. Theor. Chem. Accounts 2009, 126, 265-273. [CrossRef]

38. Meyer, R.; Lemire, C.; Shaikhutdinov, S.K.; Freund, H.-J. Surface chemistry of catalysis by gold. Gold Bulletin 2004, 37, 72-124. [CrossRef]

39. Grisel, R.; Weststrate, K.; Gluhoi, A.; Nieuwenhuys, B.E. Catalysis by gold nanoparticles. Gold Bulletin 2002, 35, 39-45. [CrossRef]

40. Hussain, A.; Ferre, C.D.; Gracia, J.; Nieuwenhuys, B.E.; Niemantsverdriet, J.W. DFT study of CO and NO adsorption on low index and stepped surfaces of gold. Surf. Sci. 2009, 603, 2734-2741. [CrossRef] 
41. Davis, S.P.; Abrams, M.C.; Brauet, J.W. Fourier-Transform Spectroscopy; Academic Press: New York, NY, USA; London, UK, 2001; p. 261.

42. Doyen, G.; Ertl, G. Theory of carbon monoxide chemisorption on transition metals. Surf. Sci. 1974, 43, 197-229. [CrossRef]

43. Hussain, A.; Muller, A.; Nieuwenhuys, B.E.; Gracia, J.; Niemantsverdriet, J. (Hans) Two Gold Surfaces and a Cluster with Remarkable Reactivity for CO Oxidation, a Density Functional Theory Study. Top. Catal. 2011, 54, 415-423. [CrossRef]

44. Wang, Y.-G.; Yoon, Y.; Glezakou, V.-A.; Li, J.; Rousseau, R. The Role of Reducible Oxide-Metal Cluster Charge Transfer in Catalytic Processes: New Insights on the Catalytic Mechanism of CO Oxidation on Au/TiO2 from ab Initio Molecular Dynamics. J. Am. Chem. Soc. 2013, 135, 10673-10683. [CrossRef]

45. Camellone, M.F.; Kowalski, P.M.; Marx, D. Ideal, defective, and gold-promoted rutile TiO 2 (110) surfaces interacting with CO, H2, and H2O: Structures, energies, thermodynamics, and dynamics from PBE +U. Phys. Rev. B 2011, 84, 035413. [CrossRef]

46. Harding, C.; Habibpour, V.; Kunz, S.; Farnbacher, A.N.-S.; Heiz, U.; Yoon, B.; Landman, U. Control and Manipulation of Gold Nanocatalysis: Effects of Metal Oxide Support Thickness and Composition. J. Am. Chem. Soc. 2009, 131, 538-548. [CrossRef] 